\title{
The role of GLI-SOX2 signaling axis for gemcitabine resistance in pancreatic cancer
}

\author{
Yanfei Jia ${ }^{1,2} \cdot$ Dongsheng $\mathrm{Gu}^{2} \cdot$ Jun $\mathrm{Wan}^{3} \cdot$ Beiqin $\mathrm{Yu}^{2,4} \cdot$ Xiaoli Zhang ${ }^{2} \cdot$ E. Gabriela Chiorean ${ }^{5} \cdot$ Yunshan Wang $^{1} \cdot$ \\ Jingwu Xie $\mathbb{C}^{2}$
}

Received: 27 July 2017 / Revised: 3 August 2018 / Accepted: 14 September 2018 / Published online: 31 October 2018

(c) The Author(s) 2018. This article is published with open access

\begin{abstract}
Pancreatic cancer, mostly pancreatic ductal adenocarcinomas (PDAC), is one of the most lethal cancers, with a dismal median survival around 8 months. PDAC is notoriously resistant to chemotherapy. Thus far, numerous attempts using novel targeted therapies and immunotherapies yielded limited clinical benefits for pancreatic cancer patients. It is hoped that delineating the molecular mechanisms underlying drug resistance in pancreatic cancer may provide novel therapeutic options. Using acquired gemcitabine resistant pancreatic cell lines, we revealed an important role of the GLI-SOX2 signaling axis for regulation of gemcitabine sensitivity in vitro and in animal models. Down-regulation of $G L I$ transcriptional factors (GLI1 or GLI2), but not SMO signaling inhibition, reduces tumor sphere formation, a characteristics of tumor initiating cell (TIC). Down-regulation of GLI transcription factors also decreased expression of TIC marker CD24. Similarly, high SOX2 expression is associated with gemcitabine resistance whereas down-regulation of $S O X 2$ sensitizes pancreatic cancer cells to gemcitabine treatment. We further revealed that elevated SOX2 expression is associated with an increase in GLII or GLI2 expression. Our ChIP assay revealed that GLI proteins are associated with a putative Gli binding site within the SOX2 promoter, suggesting a more direct regulation of $S O X 2$ by GLI transcription factors. The relevance of our findings to human disease was revealed in human cancer specimens. We found that high SOX2 protein expression is associated with frequent tumor relapse and poor survival in stage II PDAC patients (all of them underwent gemcitabine treatment), indicating that reduced $S O X 2$ expression or down-regulation of $G L I$ transcription factors may be effective in sensitizing pancreatic cancer cells to gemcitabine treatment.
\end{abstract}

These authors contributed equally: Yanfei Jia, Dongsheng Gu

Electronic supplementary material The online version of this article (https://doi.org/10.1038/s41388-018-0553-0) contains supplementary material, which is available to authorized users.

Yunshan Wang

w_yunshan@126.com

$\triangle$ Jingwu Xie

jinxie@iu.edu

1 Central Laboratory, Jinan Central Hospital Affiliated to Shandong University, Jinan, China

2 Wells Center for Pediatric Research, Department of Pediatrics, Indiana University school of Medicine, Indianapolis, IN 46202, USA

\section{Introduction}

The overall survival of cancer patients has significantly improved in the last decade due to the use of multidisciplinary care, improved chemotherapeutic agents, development of novel targeted biologic agents in combination of cancer genomic profiles and improved palliative care services [1]. In contrast, the overall survival of pancreatic cancer patients, particularly patients with pancreatic

3 Department of Molecular and Medical Genetics, Indiana University Simon Cancer Center, Indiana University, Indianapolis, IN 46202, USA

4 Shanghai Key Laboratory of Gastric Neoplasms, Shanghai Institute of Digestive Surgery, Ruijin Hospital, Shanghai Jiao Tong University School of Medicine, Shanghai 200025, China

5 Division of Medical Oncology, University of Washington, and Fred Hutchinson Cancer Research Center, 825 Eastlake Ave E, G4-833, Seattle, WA 98109-1023, USA 


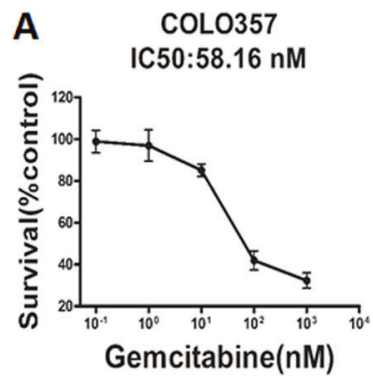

B

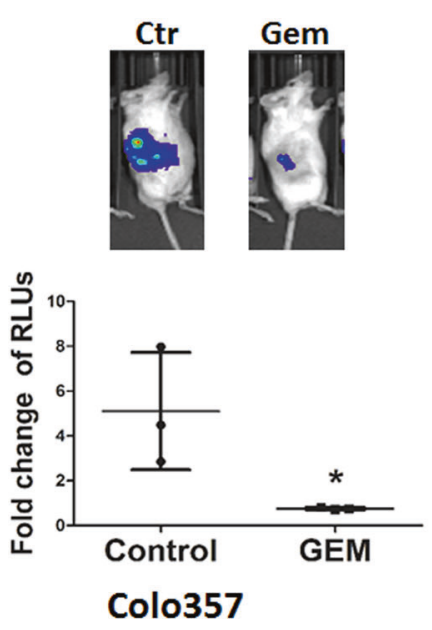

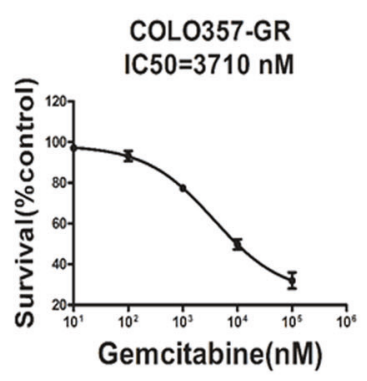
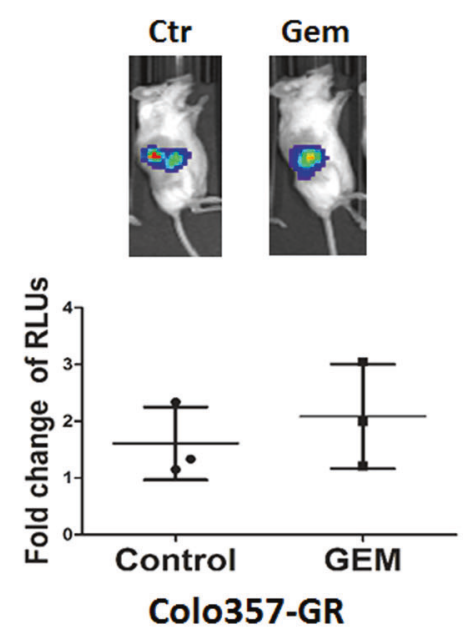

BXPC3

IC50:40.15 nM

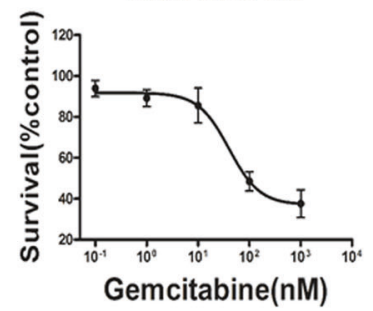

$C_{2500}$
BXPC3-GR

IC50:3273 nM

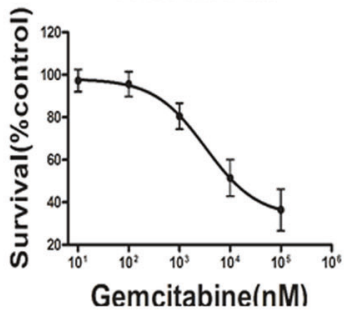

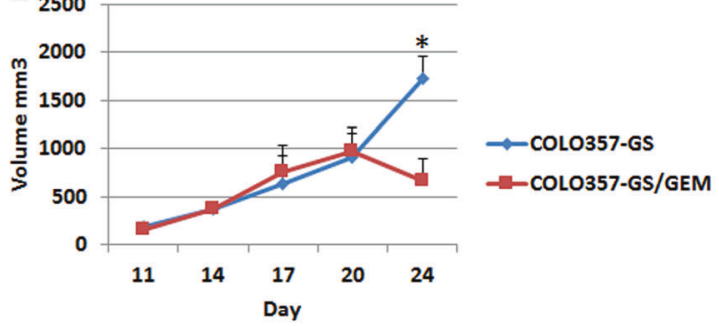

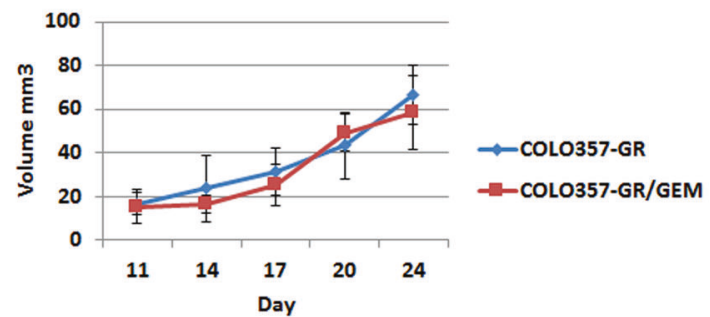

Fig. 1 Characterization of gemcitabine resistance of pancreatic cancer cells. a shows the IC50 values for gemcitabine in COLO357, COLO357-GR, BXPC3 and BXPC3-GR cells. Data points are average of duplicate wells from two independent assays. $\mathbf{b}$ shows a different response of COLO357 in comparison with COLO357-GR to gemcitabine in orthotopic pancreatic cancer models. c shows the growth curves of subcutaneous tumors following gemcitabine treatment or left untreated (vehicle control). The top shows the tumor growth curve from Colo357 parental cells (shown as Colo357-GS), and the bottom shows the tumor growth curve from Colo357-GR cells (shown as Colo357-GR). Gemcitabine treatment group was shown as GEM. *p value $<0.05$ based on Student's $t$ test ductal adenocarcinomas (PDAC), has not changed very much in the last 40 years [1-4]. Upon diagnosis, PDAC patients have a dismal median survival around 8 months and $\sim 8 \%$ 5-year survival rate. Pancreatic cancer is predicted to be number two cancer killer by 2030 [4]. The notorious resistance of pancreatic cancer to the traditional cytotoxic chemotherapeutical agents and targeted therapy poses major challenge in reducing the death toll from this deadly disease.

Gemcitabine has been the first line therapeutic agent for patients with advanced pancreatic cancer since 1997 [3]. Despite initial responsiveness to gemcitabine, pancreatic cancer eventually develops resistance, and patients succumb to the disease. Gemcitabine is a deoxycytidine analog with specific spectrum of activity and several unique properties. Gemcitabine is known to kill cells with active DNA synthesis by blocking the G1/S transition. Combining albumin-bound paclitaxel with gemcitabine has shown clear therapeutic advantage than gemcitabine alone (8.5 vs.
6.7 months in median survival) [5]. The exact molecular mechanisms underlying gemcitabine resistance in pancreatic cancer is not completely understood. Previous study indicates that stromal hedgehog signaling may be responsible for lack of gemcitabine penetration to the tumor in the mouse model. It was thus predicted that inhibition of hedgehog signaling may be effective in promoting gemcitabine efficacy [6]. However, clinical trials combining gemcitabine and hedgehog inhibitor IPI-262 did not benefit the pancreatic cancer patients, and we believe our study explains why the clinical trials failed. Gemcitabine resistance can be either intrinsic or acquired. It has been hoped that strategies to overcome gemcitabine resistance may be effective in prolonging the lifespan of pancreatic cancer patients.

In this study, we analyzed gemcitabine resistant cell lines by comparison with their matched sensitive counterparts. We discovered up-regulation of the GLI-SOX2 signaling axis in the resistant cells, which is consistent with published 
A
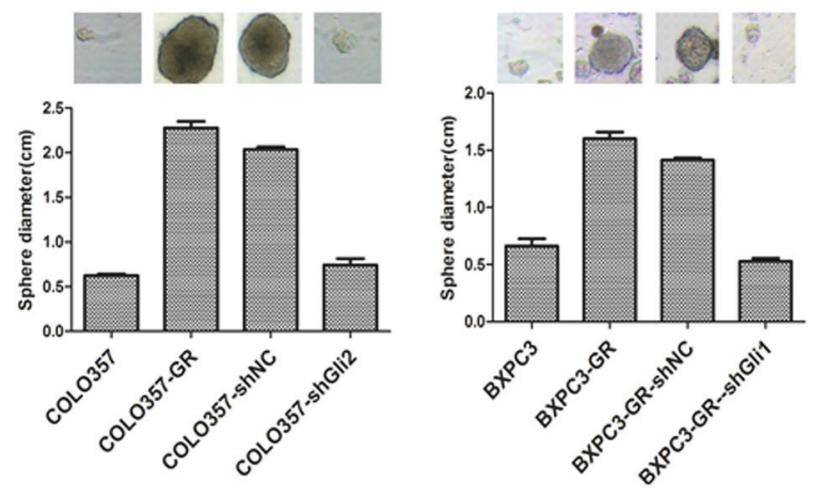

D
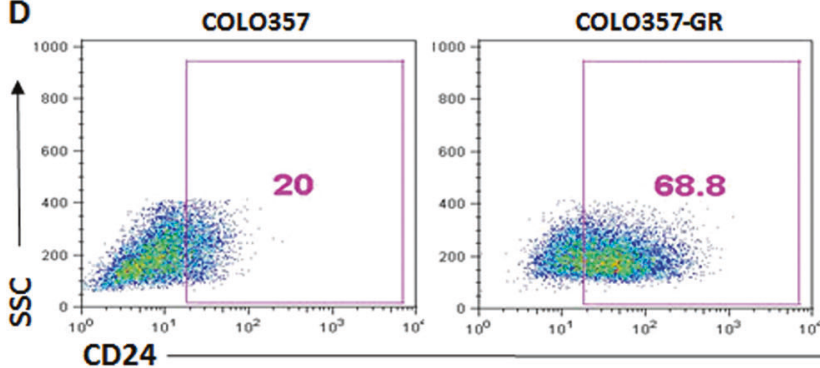

E

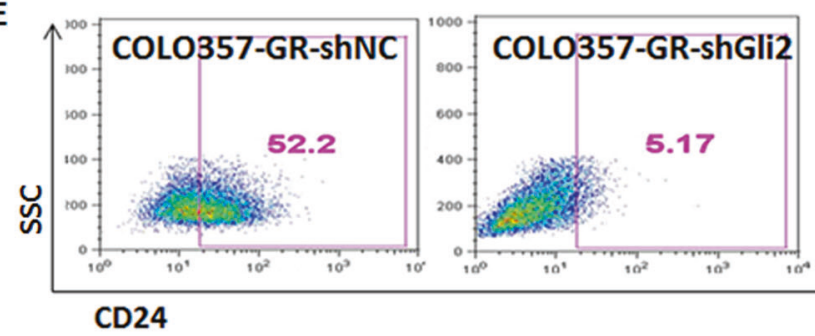

Fig. 2 Association of elevated $G L I$ expression with tumor sphere formation and CD24 expression. a shows a summary of tumor sphere data in gemcitabine resistant Colo357 cells (shown as Colo357-GR) and the parental cells (shown as Colo357) on the left, and gemcitabine resistant $\mathrm{BxPC} 3$ (shown as $\mathrm{BxPC} 3-\mathrm{GR}$ ) and the parental cells (shown as $\mathrm{BxPC} 3$ ) on the right. The top shows the typical tumor sphere morphology, and the bottom panel shows the average diameter of the tumor spheres. b shows the relative expression of $\mathrm{Hh}$ pathway

data that support the role of cancer stem cells is drug resistance [7-9]. We have performed a number of experiments to prove the significance of this signaling axis for gemcitabine resistance both in cultured cells and in animal models. We have detected regulation of SOX2 by GLI transcriptional factors in pancreatic cancer cells. The relevance of our data to pancreatic cancer was reflected by the significant association between a high SOX2 protein level with an increased risk of tumor relapse and a poor survival of pancreatic cancer patients who underwent gemcitabinebased chemotherapy.
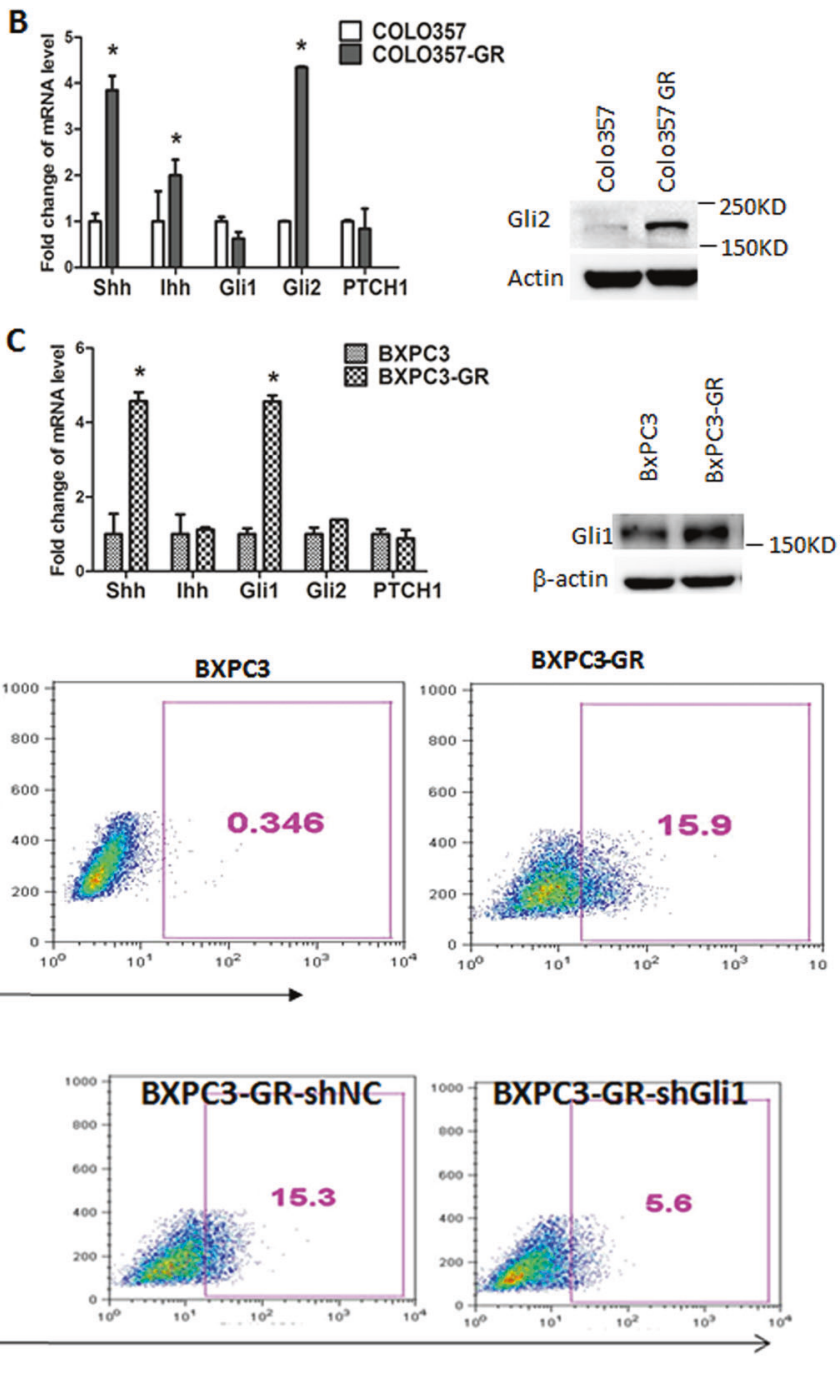

molecules in Colo357 cells using quantitative PCR (qPCR). $\mathbf{c}$ shows the relative expression of $\mathrm{Hh}$ pathway molecules in BxPC3 cells using quantitative PCR (qPCR). We also detected GLI1 and GLI2 proteins (shown at the right). d shows flow cytometry data of CD24 positivity (percentage) in different cell lines. e shows CD24 positivity (as percentage) in difference cell lines after shRNA expression. ${ }^{*} p$ value $<$ 0.05 based on Student's $t$ test

\section{Results}

\section{Molecular characterization of gemcitabine resistant pancreatic cancer cells}

To understand the molecular basis of gemcitabine resistance, we first characterized two gemcitabine resistant cell lines established from their corresponding parental cell lines Colo357 and BxPC3 following multiple treatments with gemcitabine. The IC50 for gemcitabine in the resistant Colo357 cells (named as Colo357-GR) is $3710 \mathrm{nM}$ whereas 
that of the parental cells is only $58.16 \mathrm{nM}$. The calculated resistant index (RI) [10-12] is $~ 63.8(=3710 / 58.16)$, indicating a significant gemcitabine resistance in Colo357-GR. Similarly, the IC50 for resistant BxPC3 cells (named as BxPC3-GR) is $3273 \mathrm{nM}$ whereas that for the parental cells is $40.15 \mathrm{nM}$. The RI for BxPC3-GR is also very high (81.5 $=3273 / 40.15$ ) (Fig. 1a).

We further tested the response of Colo357-GR-derived tumors to gemcitabine treatment in the immune deficient NSG mice following pancreatic injection. Our results showed that gemcitabine $(25 \mathrm{mg} / \mathrm{kg}$ via tail vein) had no effects on tumors from Colo357-GR cells but significantly reduced the tumors derived from the parental Colo357 cells (Fig. 1b). We also performed subcutaneous injection of Colo357-GR and the parental Colo357 cells, and performed gemcitabine treatment after tumors were formed. We found that the tumors derived Colo357 continued to grow, the tumors derived from the parental Colo357 cells shrunk after gemcitabine treatment (Fig. 1c). The data from both orthotopic and subcutaneous models gave essentially the same result: tumors derived from Colo357-GR cells are indeed gemcitabine resistant in mice. Similarly, we found that tumors from gemcitabine resistant BxPC3-GR cells are not sensitive to gemcitabine in comparison with their parent cells (as BxPC3-GS) (Fig. S1). These data confirm that the tumors derived from these gemcitabine resistant cells do not respond well to gemcitabine treatment.

Previous studies indicate that residual cancer cells or the putative tumor initiating cells (TICs) may be responsible for chemo-resistance [13]. Putative TICs are characterized as cells forming tumor sphere efficiently, and are regulated by several signaling pathways involved in embryonic development, such as wnt, hedgehog and notch signaling [1416]. We compared tumor sphere formation between the resistant Colo357-GR and their matched parental cells, and found that Colo357-GR cells formed large and round spheres whereas the parental cells barely formed any spheres (Fig. 2a left). This phenomenon is not cell linespecific because BxPC-GR cells also formed larger tumor spheres in comparison with the parental BxPC3 cells (Fig. $2 \mathrm{a}$ right). This observation suggests the presence of more TICs in the resistant cells.

Next, we compared gene expression in pathways responsible for maintenance of residual cancer cells or tumor initiating cells. Hedgehog, Wnt and Notch signaling pathways play important roles in embryonic development, and are critical for maintenance of putative TICs [14-16]. As shown in Fig. 2b and Fig. 2c, we found that GLI molecules (GLII or GLI2) were significantly up-regulated in the gemcitabine resistant cells. Tumors formed from Colo357-GR had higher GLI2 expression than those derived from Colo357 parental cells (see Fig. S2), which is consistent with gene expression in cell lines (Fig. 2b). We confirmed high GLI2 protein expression in the gemcitabine resistant Colo357-GR cells (Fig. 2b right). With specific antibodies to GLI1, we confirmed GLI1 protein expression in BxPC3 and BxPC3-GR cells (Fig. 2c right). In the two pairs of cell lines, we did not detect GLII isoforms GLIISN and $t G L I I[17,18]$, suggesting that elevated $G L I 1$ expression was mainly from the full-length GLII.

In our previous studies, we have shown that hedgehog signaling activation is one of the major underlying mechanisms for chemotherapy resistance in gastric and colorectal cancers $[19,20]$, indicating that $\mathrm{Hh}$ signaling may be responsible for gemcitabine resistance in pancreatic cancer. In contrast, we did not observe significant gene expression changes in DKK1, JAG2 or CTGF, molecules involved in Wnt, Notch and Hippo/YAP signaling (see Fig. S3).

To determine whether our data from two independent cell lines are also present in other pancreatic cancer cells, we searched published gene expression data on gemcitabine resistant cell lines from GEO database. The dataset GSE35141 showed high expression of hedgehog signaling molecules or target genes in gemcitabine resistant cells. For examples, GLII and GLI2 were activated by 3.0 -fold ( $p=$ $6.5 \mathrm{E}-3)$ and 2.7 -fold $(p=1.4 \mathrm{E}-2)$, respectively, in resistant PK-1 cells compared to the parental ones. GLI2 was also expressed at 23-fold ( $p=1.4 \mathrm{E}-5)$ in resistant PK-9 cell line. Thus, it appears that up-regulated hedgehog signaling is a signature for gemcitabine resistance in several pancreatic cancer cell lines.

To further characterize the residual cancer cells or tumor initiating cells, we examined cell surface markers in these cells. Expression of CD24, CD44, and ESA are enriched in pancreatic cancer stem cells [21]. In BxPC3, Colo357 as well as the derived gemcitabine resistant cell lines, CD44 and ESA are highly expressed. We did find more CD24 positive cells in the gemcitabine resistant cells (Colo357GR $>68 \%$; Colo357 20\%; $\quad$ BxPC3-GR 16\%; BxPC3 0.3\%, $p=0.0061$ ) (Fig. 2d), suggesting that gemcitabine resistant cell lines have a high percentage of putative TICs. We also examined expression of several signaling molecules whose expression has been associated with chemo-resistance in other cancer types, such as ABCG2, c-FLIP, BCL2 [22-24]. However, we did not observe significant changes in these genes (see Fig. S4).

The above characterization of two pairs of cell lines allows us to investigate the underlying mechanisms for gemcitabine resistance in pancreatic cancer cells.

\section{Regulation of the putative TIC population and gemcitabine resistance in pancreatic cancer cells}

To directly test the significance of hedgehog signaling for putative TIC maintenance, we detected the putative TIC population in pancreatic cancer cells using two approaches. 
First, we measured tumor sphere formation efficiency in Colo357-GR cells with GLI2 shRNAs (as Colo357-GRshGli2) or Colo357-GR cells with a scrambled shRNA (as Colo357-GR-shNC). Tumor sphere formation efficiency is a known biological readout of TICs [25]. We found that GLI2 knockdown significantly reduced the size of tumor spheres (Fig. 2a left). In BxPC3-GR cell line in which GLII is up-regulated, knockdown of GLII reduced the size of tumor spheres (Fig. 2a right). These results indicate that GLI transcription factors are required for tumor sphere formation in the gemcitabine resistant cells.

Second, we detected cell surface marker expression following alteration of GLI2 level in Colo357-GR. We found that GLI2 knockdown significantly reduced expression of CD24 (Fig. 2e). Similar results were also observed in BxPC3-GR cells (Fig. 2e). These data indicate that reduced Hh signaling decreases expression of putative TIC surface marker CD24. We also examined ALDH + cells and side population, but did not find any difference between the gemcitabine resistant cells and the parental cells (data not shown).

From the above data, we conclude that $\mathrm{Hh}$ signaling activation is important for maintenance of the putative TIC population as indicated by tumor sphere formation and expression of putative TIC surface marker CD24.

Furthermore, we determined whether knockdown GLII or GLI2 affect gemcitabine sensitivity in the resistant cells. When GLI2 shRNAs were expressed in Colo357-GR, we found a significant decrease in gemcitabine IC50 (Fig. 3a). Similarly, when GLI1 shRNAs were expressed in BxPC3GR, the IC50 was also significantly reduced (Fig. 3b).

The specificity of GLII and GLI2 shRNAs was tested by ectopic expression of GLII in GLII-shRNAs-expressing BxPC3 cells (or ectopic expression of GLI2 in Colo357GR-shGli2 cells). We found that ectopic expression of GLI1 reversed the phenotype of GLII shRNAs in BxPC3-GR cells and became more resistant (Fig. 3c left), and the similar results were also obtained using ectopic GLI2 expression in Colo357-GR cells (Fig. 3c left). These results indicate the specificity of GLII and GLI2 shRNAs, and further confirm that elevated expression of $G L I$ transcription factors is sufficient to drive gemcitabine resistance.

We noticed elevated expression of $\mathrm{SHH}$ and $\mathrm{IHH}$ in the resistant cells, and thought that elevated expression of GLII or GLI2 in the resistant cells may be through hedgehog ligand-mediated signaling. In that case, Smoothened antagonist BMS833923 [26] should be sufficient to reduce IC50 for gemcitabine. However, our data showed that BMS833923 only reduced gemcitabine IC50 by less than $50 \%$ (Fig. 3a, b). Furthermore, BMS833923 was not as effective as $G L I$ specific shRNAs in reducing expression of GLI1 (in BxPC3-GR cells) or GLI2 (in Colo357-GR cells). These data indicate that ligand-independent (non-canonical) hedgehog signaling plays a more important role in gemcitabine resistance. This result is consistent with the failed clinical trials using Smoothened antagonists [27-29]. Currently, the exact mechanisms responsible for this noncanonical Hh signaling activation are under investigation.

To assess whether tumors formed from these cells respond to gemcitabine as expected, we treated tumorbearing mice with gemcitabine. After tumors develop to certain size following injection of different cancer cells (Colo357-GS; Colo357-GR; Colo357-GR-shNC; Colo357GR-Gli2-shRNAs), we treated mice with gemcitabine (25 $\mathrm{mg} / \mathrm{kg}$, twice weekly). Although Colo357-GS cells formed relative large tumors, the tumors shrank rapidly after gemcitabine treatment. In contrast, Colo357-GR-formed tumors did not respond to gemcitabine treatment as we had expected (Fig. 4a). When GLI2shRNAs were expressed in Col357-GR cells, GLI2 expression was significantly reduced (Fig. 4b), and tumors became sensitive to gemcitabine (Fig. 4A). In contrast, the shRNA control- (Colo357GR-shNC) formed tumors were not responsive to gemcitabine treatment (Fig. 4a). We have performed two types of studies in immune deficient NSG mice: orthotopic mouse model following pancreatic injection of luciferaseexpressing cells [26] or subcutaneous injection of cells (Fig. 4c). Our data from both models indicate that Gli transcription factors are essential factors in mediating gemcitabine resistance in pancreatic cancer.

Similarly, we found that while tumors derived from BxPC3-GR were less sensitive to gemcitabine (Fig. S1), GLI1 gene knockdown using specific shRNAs sensitized tumors (for the tumors derived from BxPC-GR-shGLII) to gemcitabine treatment (Figure S5).

Taken together, we found that elevated GLI1 and GLI2, but not the ligands $S H H$ and $\mathrm{IHH}$, is required for the acquired gemcitabine resistance in pancreatic cancer both in cultured cells and in mice. We believe that hedgehog signaling exerts its functions through regulation of the putative TICs.

\section{Regulation of SOX2 by hedgehog signaling in gemcitabine resistant cells}

A number of transcription factors have been reported to regulate putative TICs, and we assessed expression of these factors [30-37] in the resistant cells, and found that expression of SOX2 was highly elevated (Fig. 5a). A significant increase in SOX2 protein level was also observed (Fig. 5b) in the resistant cells.

It is known that sex-determining region Y-box 2 (Sox2) is of vital importance in regulation of stem cells in embryos and in cancer [38]. In the tumors derived from Colo357-GR, we found a higher level of SOX2 in comparison to the parental COLO357 cells (see Fig. 5c). The relevance of 

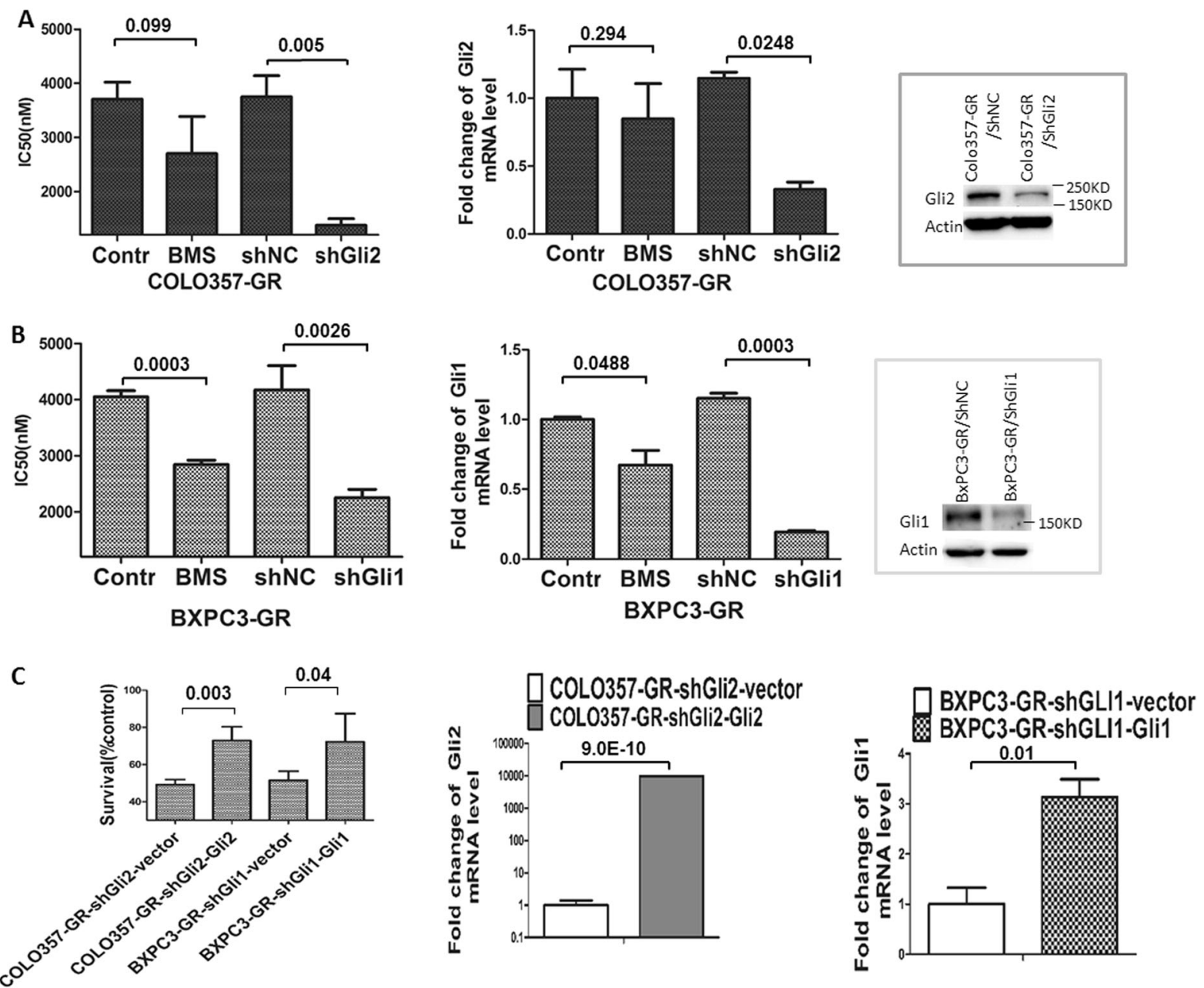

Fig. 3 Reduced expression of GLI transcription factors, but not SMO inhibition, sensitizes pancreatic cancer cells to gemcitabine treatment. a shows the treated data from SMO antagonist BMS-833923 (shown as BMS in the figure) or GLI2-shRNAs in COLO357-GR cells. GLI2 shRNAs, but not BMS-833923, were more effective in sensitizing COLO357-GR cells to gemcitabine treatment (left). GLI2 shRNAs reduced expression of GLI2 while BMS833923 had little effects (right). b shows the data from treatment with BMS-833923 or GLI1shRNAs in BXPC3-GR cells. GLI1 shRNAs, but not BMS833923, were more effective in sensitizing BXPC3-GR cells to gemcitabine

SOX2 expression to human pancreatic cancer specimens was investigated using a tissue array assembled with surgically removed specimens from stage II pancreatic cancer patients enrolled in our medical center. All the patients had stage II PDAC tumors and underwent chemotherapy with gemcitabine as the first line treatment. This tissue array is suitable for protein detection by immunohistochemistry. We examined SOX2 protein expression by immunohistochemistry (Fig. 5d), and found that some tumors with higher SOX2 protein expression while others express a low level of SOX2. Since all patients had used gemcitabine following surgery, tumor relapse following gemcitabine treatment may result in a short survival of patients. We performed treatment (left). The GLII level was reduced more significantly by GLI1 shRNAs than by BMS-833923 (Center). GLI1 protein was also detected by Western blotting (right). c shows the specificity of shRNAs by re-expression of GLII or GLI2 and their effects on cell viability after gemcitabine $(2 \mathrm{mM})$ treatment. Overexpression of GLI2 or GLI1 increased gemcitabine resistance in COLO357-GR-shGli2 and BXPC3-GR-shGli1 cells (left). Expression of GLII (bottom right) and GLI2 (bottom left) was detected by real-time PCR. $p<0.05$ was regarded as significant changes

Kaplan-Meier analysis for these patients, and found that patients with a high SOX2 protein expression had poor survival $(p<0.05)$ (Fig. 5e). These results suggest that a high protein expression of SOX2 indicates poor prognosis of gemcitabine treatment and patient survival.

To determine the functional relevance of SOX2 expression with gemcitabine sensitivity in pancreatic cancer cells, we knocked down SOX2 expression by two independent shRNA constructs in the gemcitabine resistant cell lines and treated with gemcitabine afterwards. As indicated in Fig. 6a $\& 6 \mathrm{~b}$, down-regulation of $S O X 2$ significantly reduced the IC50 of gemcitabine in the resistant cancer cells. For example, Colo357-GR cells with SOX2shRNA expression 
A

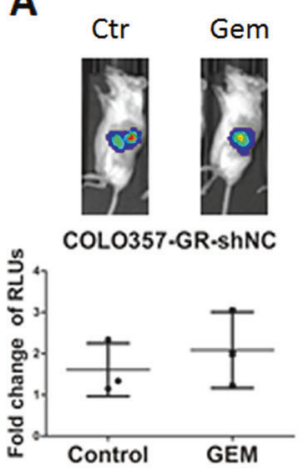

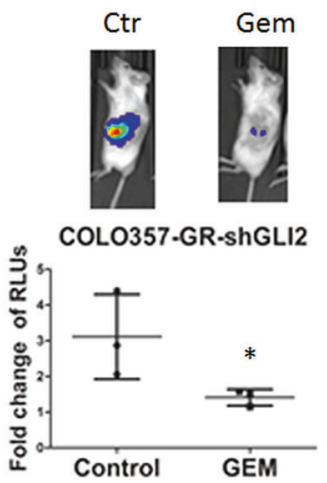

B

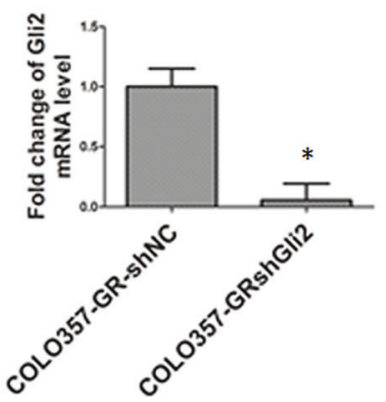

C

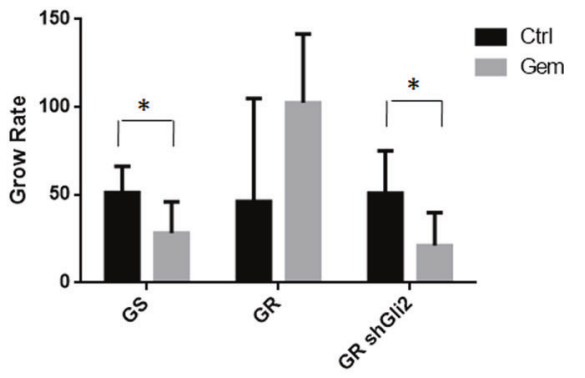

Fig. 4 The effect of GLI2 knockdown on gemcitabine response in an orthotopic mouse model. a shows the effect of GLI2 knockdown in tumor response to gemcitabine in mice (left for the Colo357-GR-shNC as control, right for Colo357-GR-shGLI2). b shows down-regulation of Gli2 as confirmed by qPCR analysis. c shows the data from

has an IC50 of gemcitabine $<1000 \mathrm{nM}$ in comparison with the IC50 of Colo357-GR with control shRNA above 3000 nM. Similarly, SOX2shRNAs reduced the IC50 of BxPC3GR from over $3000 \mathrm{nM}$ to less than $2000 \mathrm{nM}$ (Fig. 6a, b). SOX2 shRNAs also reduced the level of CD24 positivity in the resistant cells (Fig. 6c), just like GLI2 shRNAs in Colo357 cells (Fig. 2e). These results indicate that SOX2 is at least partly responsible for gemcitabine sensitivity.

Next, we investigated how SOX2 expression was induced in the resistant pancreatic cancer cells. We have evidence to indicate that the level of GLII/2 is correlated to SOX2 expression. First, knockdown of GLI2 (Fig. 7a) or GLII (Fig. 7b) was associated with reduced expression of SOX2. Second, re-expression of GLII or GLI2 induced SOX2 expression (Fig. 7c). In the mouse model, tumors formed from Colo357-GR, in which GLI2 is highly expressed, had more SOX2 expression in comparison with the tumors from the parental Colo357 cells (Fig. 7d). Thus, it appears that the level of SOX2 expression is controlled by GLII/2 expression.

To further determine whether SOX2 expression is transcriptionally regulated by $G L I$ molecules, we analyzed the promoter sequence of human $S O X 2$, and discovered a $G L I$ consensus binding site (Fig. 8a). We performed ChIP assays in Colo357-GR and in BxPC3-GR cells following ectopic expression of GLI2 and GLI1 respectively. The genomic DNAs associated with GLI2 and GLI1 proteins were immunoprecipitated using specific tag antibodies, and the corresponding GLI binding DNA fragment was detected by PCR amplification with the flanking primers. We found that antibodies against ectopically expressed GLI1 and GLI2 proteins, but not the control IgG, were able to immunoprecipitate the DNA fragment containing the consensus GLI binding sequence (Fig. 8a, b). In contrast, an un-related DNA fragment was not detected in this assay (Fig. 8b). These results indicate that elevated SOX2 expression in the subcutaneous tumors (GS as Colo357 parental cells; GR as Colo357gemcitabine resistant cells; GR-shGLI2 as GLI2 shRNA expressing Colo357-GR cells). Statistically significant findings were denoted when $* p<0.05$

resistant cells may be transcriptionally regulated by $G L I$ molecules.

Taken all the data together, we found that acquired gemcitabine resistant pancreatic cancer cells have elevated expression of GLI transcription factors, either GLII or GLI2, which is associated with elevated $S O X 2$ expression. We discovered that knockdown of GLI molecules (GLII in BxPC3-GR, or GLI2 in Colo357-GR) or SOX2 sensitizes these cells to gemcitabine treatment. We have evidence to indicate that SOX2 expression is regulated by GLI molecules, possibly through transcriptional regulation. The relevance of our findings to human cancer is reflected by the fact that high level of SOX2 protein expression is associated with a poor patient survival in a cohort of stage II pancreatic cancer patients following gemcitabine treatment. Thus, the disruption of the GLI-SOX2 signaling axis may be effective in sensitizing pancreatic cancer to gemcitabinebased therapy.

\section{Discussion}

Our findings reveal an important mechanism underlying drug resistance in pancreatic cancer, one of the deadest cancer types. We showed that the Gli-Sox 2 signaling axis is elevated in pancreatic cancer cells with acquired gemcitabine resistance. Down-regulation of GLII, GLI2 or SOX2 sensitized pancreatic cancer cells to gemcitabine treatment. We have evidence to support that SOX2 expression is regulated by GLI molecules, possibly through transcriptional regulation. The relevance of our studies was confirmed in pancreatic cancer specimens. We showed that high level of Sox 2 expression is associated with poor patient survival in stage II disease following gemcitabine treatment. Thus, it is anticipated that strategies at disrupting the GLI-SOX2 signaling axis may be effective in sensitizing 
Fig. 5 Association of SOX2 expression with gemcitabine resistance in pancreatic cancer cell lines and patient survival. a and $\mathbf{b}$ show the relative gene (a) and protein (b) expression of SOX2 in different cell lines. c shows the relative transcript level of SOX2 in the orthotopic mouse models of pancreatic cancer (Colo357-GS as colo357 parental cells and Colo357-GR as gemcitabine resistant Colo357 cells). d shows typical high and low SOX2 staining in human pancreatic cancer specimens. e shows the KaplanMeier plots of patients with high or low SOX2 expression (Longrank test). Statistically significant findings were denoted when $* p<0.05$
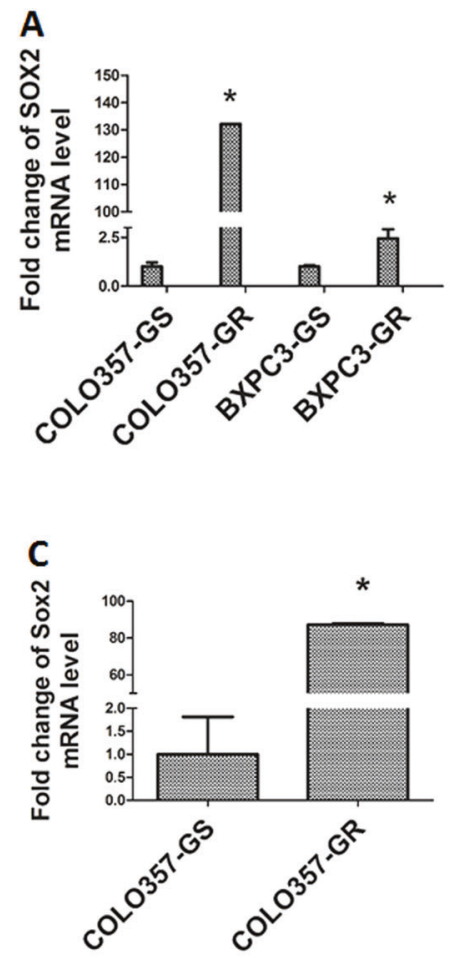

B

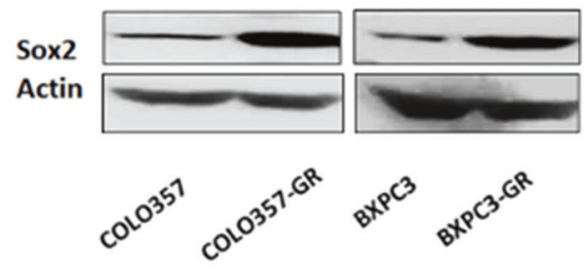

D

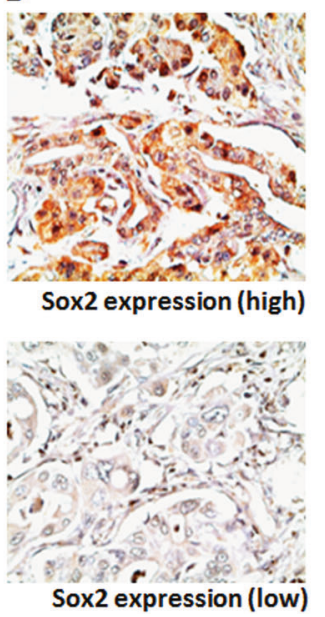

$\mathbf{E}$

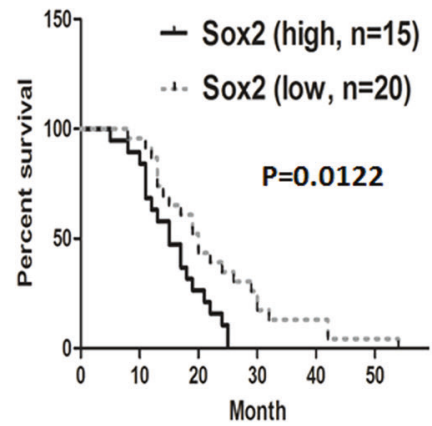

gemcitabine-based treatment, as reported in several clinical trials [27, 28, 39-41]. Currently, there are no specific GLI inhibitors approved by FDA to suppress GLI activities. Several compounds have shown activities in reducing GLI signaling, including GANT61 [42] and Arsenic trioxide (ATO) [43]. ATO has been approved by FDA for treatment of acute promyelocytic leukemia [44-46]. Further studies are needed to test whether GLI1/2 inhibitors, including GANT61, are effective in reducing drug resistance in pancreatic cancer.

Furthermore, up-regulation of SOX2 is commonly observed in other resistant cancer cells [47-49]. Resistance to chemotherapy and targeted therapies is a major issue both in the clinical care of cancer patients and in cancer research. For example, SOX2 is known to be responsible for resistance to anti-androgen based therapy in prostate cancer [49]. It remains unclear whether SOX2 expression is regulated by GLI transcription factors under these conditions. Based on these results, agents specifically targeting SOX2 may be effective in cancer therapy.

In our tissue array analysis, we discovered an association between high SOX2 protein level with poor patient survival. Thus, it appears that patients with high Sox 2 protein expression in the tumor may not suitable for gemcitabine treatment. This result should be confirmed by expression of GLII/2 molecules. However, there are no suitable GLI1/2 antibodies for immunohistochemistry, and these analyses cannot be performed in tissue arrays. Instead, we used TCGA data to determine whether high expression of SOX2 and $G L I$ molecules is associated with more cancer relapse 
A

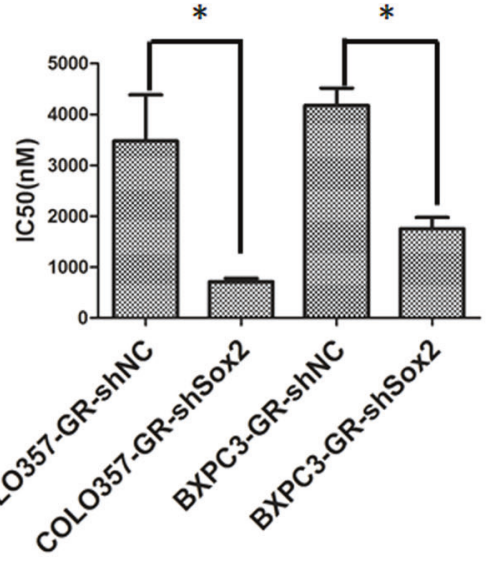

C
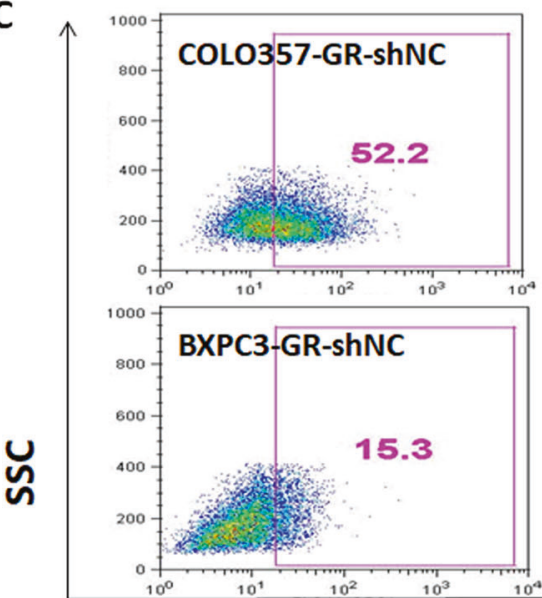

CD24

Fig. 6 The role of SOX2 in gemcitabine resistance. a shows the effect of SOX2 knockdown on gemcitabine treatment (left shows the IC50 change, right shows the relative gene expression), and $\mathbf{b}$ shows the

following gemcitabine treatment. Through cbioportal (http://www.cbioportal.org/) analysis of 186 TCGA pancreatic cancer specimens, we found that patients with high expression of GLI2 and SOX2 in the tumor had $\sim 70 \%$ chance of cancer relapse following gemcitabine treatment. In contrast, patients with low expression of GLI2 and SOX2 in the tumor had $<60 \%$ of chance of cancer relapse. These results are consistent with our hypothesis that activation of the GLI-SOX2 signaling axis is an important factor for gemcitabine resistance in pancreatic cancer.

\section{Materials and methods}

\section{Chemicals, antibodies and reagents}

Gemcitabine was purchased from Besse Medical (West Chester, OH). BMS833923 is a potent inhibitor for smoothened signaling $(\mathrm{EC} 50=50 \quad \mathrm{nmol} / \mathrm{L}) \quad[26]$.
B
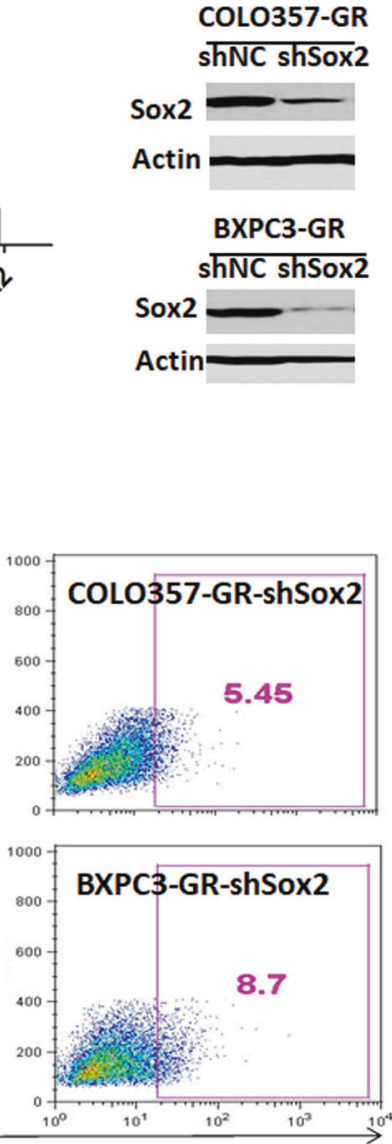

SOX2 protein level. c shows the effect of shRNAs of GLI2 (COLO357-GR), GLI1 (BxPC3-GR) and SOX2 on CD24 positivity following flow cytometry analysis

BMS833923 was provided by Bristol-Myers Squibb [5052]. Antibodies to GLI1 (Cat\#2534, Cell Signaling Technology, Danvers, MA, USA) and SOX2 (Cat\# 97959, Abcam, Cambridge, UK) were purchased commercially; Gli2 antibodies were provided by Dr. CC Hui [53]. Other antibodies include Myc-Tag (Cat\# 9B11, Cell Signaling Technology, Danvers, MA, USA); Flag-Tag (Sigma, St. Luis, MO, USA); CD24 (clone ML5), histone H3 and IgG (BioLegend, San Diego, CA, USA).

Cell lines Colo357 and BxPC3 cells were obtained from the American Type Culture Collection (ATCC), and maintained according to the vendor's instruction. In order to generate cell lines resistant to gemcitabine, Colo357 and BxPC3 cells were exposed to increasing concentrations of gemcitabine. Finally, Colo357-GR (gemcitabine resistance) and BxPC3-GR were maintained in the presence of $500 \mathrm{nM}$ gemcitabine. All cell lines have been tested for their authenticity. 
Fig. 7 Regulation of $S O X 2$ by GLII and GLI2. a shows SOX2 expression following treatment with BMS-833923, a specific inhibitor for SMO or expression of GLI2 shRNAs in COLO357-

GR cells. b shows Sox2 expression following treatment with BMS-833923, a specific inhibitor for SMO or expression of GLI2 shRNAs in BxPC3-GR cells. c shows regulation of SOX2 by ectopic expression of GLII and GLI2 in COLO357 and BxPC3 cells (similar to Fig. $3 c)$. $\mathbf{d}$ shows reduced expression of SOX2 by GLI2 shRNAs in tumors derived from COLO357GR-control shRNA and COLO357-GLI2-shRNAs in an orthotopic mouse model
A

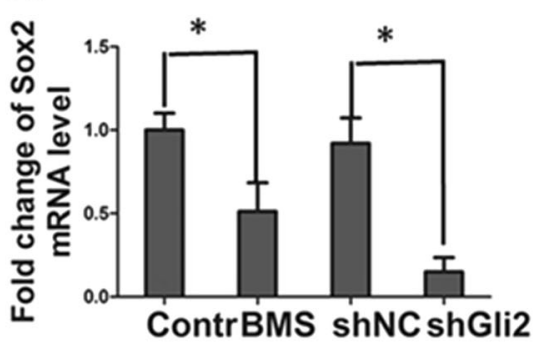

C

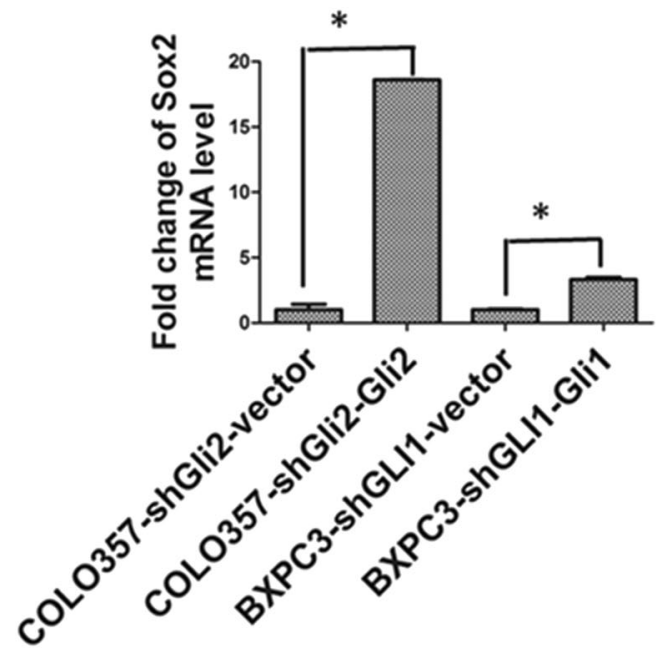

B

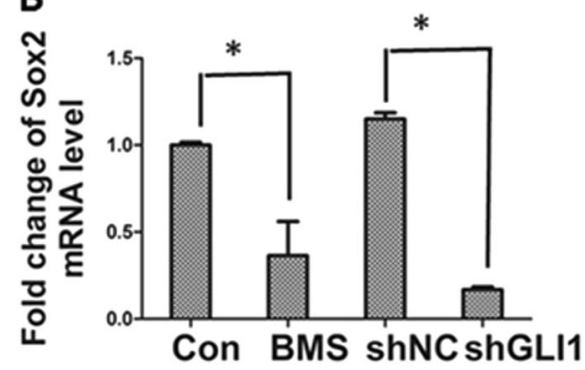

D

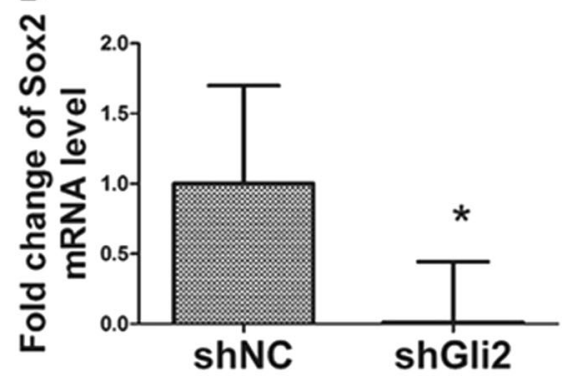

\section{Cell viability assay}

Alamar Blue assay was used to determine cell viability [5456]. 2000-4000 cells were seeded in each well of 96-well plates. Different amounts of gemcitabine were added or left untreated for specified amount of time. For cell viability, we added Alamar Blue $(10 \mathrm{ul} / \mathrm{well})$ for $2 \mathrm{~h}$ at $37^{\circ} \mathrm{C}$. Viable cells with active mitochondrial enzyme activity will generate fluorescence from Alamar Blue (Fisher Scientific), which can be measured by a plate reader (BioTek) (excitation $530 \mathrm{~nm}$; emission $590 \mathrm{~nm}$ ). IC50 values were generated from fluorescent reading using GraphPad Prism.

\section{RNA extraction, RT-PCR, and real-time PCR}

We extracted total RNAs from cultured cells or tumorous tissues using Tri-RNA extraction reagent (Sigma, St. Luis, MO, USA), and performed real-time quantitative PCR analyses according to a previously published procedure [57]. For each sample, we used triplicates and used the comparative $\mathrm{C}_{\mathrm{T}}(\Delta \Delta \mathrm{CT})$ as described by the manufacturer (Applied Biosystems/ Fisher Scientific). The relative amount of target $\left(2^{-\Delta \Delta C T}\right)$ was obtained by normalizing to an endogenous glyceraldehyde-3-phosphate dehydrogenase $(G A P D H)$ and relative to a calibrator. All primers and probes were purchased from Applied Biosystems/Fisher Scientific). RT-PCR was used to detect possible existence of GLII isoforms in the pancreatic cancer cell lines. Primers 5'-TGTTCAACTCGATGACCC-3' and 5'-GTCATGGGGACCACAAGG-3' were used to detect wild type GLII (500 bp) and truncated GLII (tGLII) (377 bp). Primers 5'GGCATCCGACAGAGGTGAGATGGAC-3' and 5'-GA GCCCAGCGCCCAGACAGA-3' or 5'-CTGTCTCAGGGAACCGTGGGTCTTTGT-3' were used to detect fulllength $G L I I$ or $G L I I \Delta N$ in pancreatic cancer cell lines.

\section{ShRNA expression and plasmids}

We purchased shRNAs specific to Gli2 or Gli1 from Sigma (St. Luis, Mo, USA) and forced their expression in cells through lentivirus-mediated expression. For every five shRNAs tested for each gene, we found at least two shRNAs with reduced expression of the target genes in this study. Plasmids for Gli1 and Gli2 expression were from our previous study [58] with a MYC (GLI1) or Flag (GLI2) tag at the $\mathrm{N}$-terminus. 


\section{A- Primer designs}

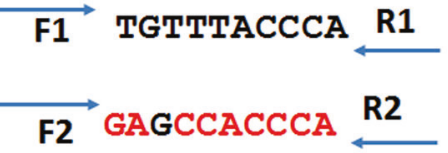

B- ChIP analysis

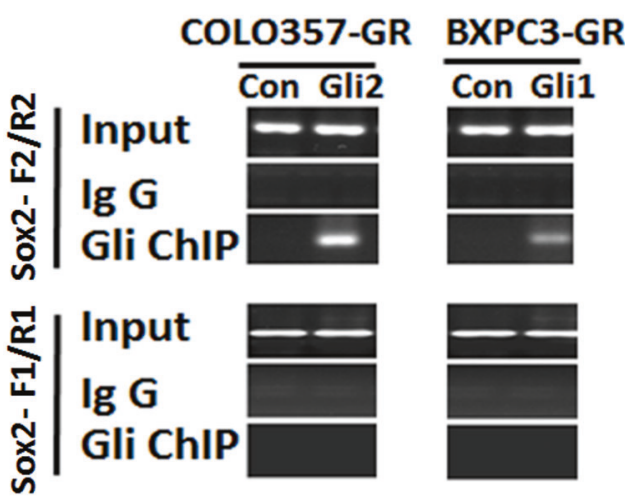

Fig. 8 Binding of SOX2 promoter fragments by GLII and GLI2 proteins as revealed by ChIP. a shows a putative GLI binding site in a PCR product from primers F1/R1 and F2/R2. b shows the PCR products generated by two pairs of primers F1/R1 (no GLI binding consensus sites) and F2/R2 (with one GLI binding consensus site) following chromatin immunoprecipitation with GLI1 (MYC) and GLI2 (Flag) antibodies (see Methods). Mouse IgG proteins were used as the negative control

\section{Flow cytometry}

We obtained single cells from cells or tissues, and subjected them to anti-CD24 antibody staining. Fluorescence labeled antibodies purchased from BioLegend (San Diego, CA, USA) were incubated with cells for $30 \mathrm{~min}$ on ice (with 1:200 dilutions).

\section{Orthotopic mouse model and subcutaneous xenografts of pancreatic cancer}

Pancreatic cancer cells (Colo357, Colo357-GR-shNC and Colo357-GR-shGLI2) with stable expression of luciferase were harvested in single cell suspension at a concentration of $1 \times 10^{6}$ cells $/ \mathrm{ml}$. A total of $2 \times 10^{5}$ cells (in $50 \mathrm{uL}$ of growth medium) were injected into pancreas of the NOD/ scid/ IL2Rgnull mice (NSG) with a 27-gauge needle as reported previously [59]. For subcutaneous xenografts, $1 \times$ $10^{6}$ cells were injected subcutaneously into NSG mice. Tumors in subcutaneous models were measured with a caliper twice a week whereas the tumor in orthotopic mouse models was measured by luciferase activity within cancer cells once a week. Two to 3 weeks after tumor transplantation, the mice were weighed and randomized (with each group with similar tumor size, with less than $20 \%$ difference among the mice and $<20 \%$ difference between groups) into two treatment groups: vehicle control or $25-\mathrm{mg} / \mathrm{kg}$ gemcitabine by i.v injection, twice per week for 2 weeks. Mice with no tumor growth will be excluded from further treatment study. Generally, we have at least three mice for each treatment group, and the experiment was carried out in both orthotopic and subcutaneous models. Mice were euthanized by carbon dioxide asphyxia after treatment. Tumor lesions in both models were harvested and divided into several portions. Some were snap-frozen in liquid nitrogen for mRNA extraction; some were embedded in paraffin; some were cut into small pieces with scissors and then digested with collagenase IV to obtain single-cell suspension for flow cytometry analysis. Animal studies were approved by Indiana University School of Medicine (IACUC\# 11370).

\section{Immunohistochemistry staining}

PDAC tissue microarray (TMA) was generated in IU School of Medicine by the Pancreatic Cancer Signature Center. The TMA contained 35 patients at IIB stage. All patients received gemcitabine chemotherapy. Overall survival was defined as the time interval between the date of histological diagnosis and the date of death from any cause. Immunohistochemistry was performed as described previously [60]. In brief, after removing paraffin and underwent a series of hydration steps, the slides were treated with endogenous peroxidase in $0.3 \% \mathrm{H}_{2} \mathrm{O}_{2}$ for $30 \mathrm{~min}$. After blocking non-specific binding sites with $1 \% \mathrm{BSA}$, tissue sections were incubated with specific SOX2 antibodies (at 1:1500 dilution) at $37^{\circ} \mathrm{C}$ in humid chambers for $2 \mathrm{~h}$. We detected the antibody binding with streptavidin-biotinperoxidase complex/HRP (VECTOR, USA) and substrate 3, 3-diaminobenzidine for $3 \mathrm{~min}$. Hematoxylin was used for counterstaining.

\section{ChIP assay}

we performed ChIP assay according to a previously reported protocol [58]. Briefly, chromatin DNA was first crosslinked by $1 \%$ formaldehyde, and genomic DNAs sheared by sonication in the presence of protease inhibitors. After removing the pellets, we performed immunoprecipitation by incubation of the aqueous phase mixture with primary antibodies against histone $\mathrm{H} 3$, Myc, Flag or IgG (as a negative control). The precipitated DNA fragments were analyzed by PCR with the following SOX2 promoter primers: Pair $1 \mathrm{~F}$ 5'-TGGTGCAGGGTACTTAAATGA-3', pair $1 \mathrm{R}$ GAGGACAGAGGTTTGGGTCT; Pair $2 \mathrm{~F}$ 5GCGTCCCATCCTCATTTAAG-3' and Pair2-R 5'AGCAACAGGTCACACCACAC' 3 '. Please note that pair1 is for the GLI-binding consensus site-containing fragment whereas pair2 is for the fragment without such a site. 


\section{Human specimens}

Collection of human specimens were approved by The Institutional research board at Indiana University with IRB Study EX0909-22. All the patient information were removed before specimens were used by the end users in this study.

\section{Statistical analyses}

Results are expressed as the mean $\pm \mathrm{SD}$. All statistical comparisons were made with a standard $t$ test (two-tailed), using biostatistics software from GraphPad Prism. Sample size was determined by POWER analysis. We predict that the difference between the treatment group and the control group will be $>50 \%$. Using Chi-Square analysis, we will need 5 mice/ group to achieve a statistically significant data (80\% POWER with type I error <0.05). We have at least 6 mice (with 3 males and 3 females) in orthotopic and subcutaneous mouse models in our study. The criteria for significance were $p<0.05$ for all comparisons.

Acknowledgements We thank you Professor Keping Xie and Dr. Zizheng Dong for help with cell line generation, and generous support from the Department of Pediatrics, The Well Center for Pediatric Research, Jeff Gordon Research Laboratory, AGA, Healthcare Initiatives, Inc., and CTSI Indiana. The bioinformatics data analysis was performed in collaboration with the Collaborative Core for Cancer Bioinformatics (C3B) shared by Indiana University Simon Cancer Center and Purdue University Center for Cancer Research with support from the Walther Cancer Foundation. This work was supported by the following grants and foundations: NIH-R01-155086; Riley Foundation for Children; National Natural Science Foundation of China (No. 31671468 and 81602593), Shandong Provincial Natural Science Foundation of China (ZR2015HM018).

Author contributions Conceptualization and Design: JX, YW. Resources: JX, YW. Methodology: YJ, DG, BY, XZ. Data Analysis and Interpretation: JW, EGC, JX. Writing, review, and/or revision of the manuscript: YJ, DG, JX. Supervision: JX.

\section{Compliance with ethical standards}

Conflict of interest The authors declare that they have no conflict of interest.

Open Access This article is licensed under a Creative Commons Attribution 4.0 International License, which permits use, sharing, adaptation, distribution and reproduction in any medium or format, as long as you give appropriate credit to the original author(s) and the source, provide a link to the Creative Commons license, and indicate if changes were made. The images or other third party material in this article are included in the article's Creative Commons license, unless indicated otherwise in a credit line to the material. If material is not included in the article's Creative Commons license and your intended use is not permitted by statutory regulation or exceeds the permitted use, you will need to obtain permission directly from the copyright holder. To view a copy of this license, visit http://creativecommons. org/licenses/by/4.0/.

\section{References}

1. Siegel RL, Miller KD, Jemal A. Cancer statistics. CA J Clin. 2017;67:7-30.

2. Gudjonsson B. Cancer of the pancreas. 50 years of surgery. Cancer. 1987;60:2284-303.

3. Vogelzang NJ, Benowitz SI, Adams S, Aghajanian C, Chang SM, Dreyer ZE, et al. Clinical cancer advances 2011: Annual report on progress against cancer from the American Society of Clinical Oncology. J Clin Oncol. 2012;30:88-109.

4. Rahib L, Smith BD, Aizenberg R, Rosenzweig AB, Fleshman JM, Matrisian LM. Projecting cancer incidence and deaths to 2030: the unexpected burden of thyroid, liver, and pancreas cancers in the United States. Cancer Res. 2014;74:2913-21.

5. Von Hoff DD, Ervin T, Arena FP, Chiorean EG, Infante J, Moore $\mathrm{M}$, et al. Increased survival in pancreatic cancer with nabpaclitaxel plus gemcitabine. N Engl J Med. 2013;369:1691-703.

6. Olive KP, Jacobetz MA, Davidson CJ, Gopinathan A, McIntyre D, Honess D, et al. Inhibition of Hedgehog signaling enhances delivery of chemotherapy in a mouse model of pancreatic cancer. Science. 2009;324:1457-61.

7. Zhang Z, Duan Q, Zhao H, Liu T, Wu H, Shen Q, et al. Gemcitabine treatment promotes pancreatic cancer stemness through the Nox/ROS/NF-kappaB/STAT3 signaling cascade. Cancer Lett. 2016;382:53-63.

8. Hong SP, Wen J, Bang S, Park S, Song SY. CD44-positive cells are responsible for gemcitabine resistance in pancreatic cancer cells. Int J Cancer. 2009;125:2323-31.

9. Zhao H, Duan Q, Zhang Z, Li H, Wu H, Shen Q, et al. Upregulation of glycolysis promotes the stemness and EMT phenotypes in gemcitabine-resistant pancreatic cancer cells. J Cell Mol Med. 2017;21:2055-67.

10. Mondesire WH, Jian W, Zhang H, Ensor J, Hung MC, Mills GB, et al. Targeting mammalian target of rapamycin synergistically enhances chemotherapy-induced cytotoxicity in breast cancer cells. Clin Cancer Res. 2004;10:7031-42.

11. Schniewind B, Christgen M, Kurdow R, Haye S, Kremer B, Kalthoff $\mathrm{H}$, et al. Resistance of pancreatic cancer to gemcitabine treatment is dependent on mitochondria-mediated apoptosis. Int $\mathrm{J}$ Cancer. 2004;109:182-8.

12. Tesei A, Ricotti L, De Paola F, Amadori D, Frassineti GL, Zoli W. In Vitro schedule-dependent interactions between the multitargeted antifolate LY231514 and gemcitabine in human colon adenocarcinoma cell lines. Clin Cancer Res. 2002; 8:233-9.

13. Abel EV, Simeone DM. Biology and clinical applications of pancreatic cancer stem cells. Gastroenterology. 2013; 144:1241-8.

14. Takebe N, Miele L, Harris PJ, Jeong W, Bando H, Kahn M, et al. Targeting Notch, Hedgehog, and Wnt pathways in cancer stem cells: clinical update. Nature reviews. Clin Oncol. 2015;12:44564.

15. Taipale J, Beachy PA. The Hedgehog and Wnt signalling pathways in cancer. Nature. 2001;411:349-54.

16. Reya T, Morrison SJ, Clarke MF, Weissman IL. Stem cells, cancer, and cancer stem cells. Nature. 2001;414:105-11.

17. Cao X, Geradts J, Dewhirst MW, Lo HW. Upregulation of VEGFA and CD24 gene expression by the tGLI1 transcription factor contributes to the aggressive behavior of breast cancer cells. Oncogene. 2012;31:104-15.

18. Shimokawa T, Tostar U, Lauth M, Palaniswamy R, Kasper M, Toftgard R, et al. Novel human glioma-associated oncogene 1 (GLI1) splice variants reveal distinct mechanisms in the terminal transduction of the hedgehog signal. J Biol Chem. 2008;283:14345-54. 
19. Zhang L, Song R, Gu D, Zhang X, Yu B, Liu B, et al. The role of GLI1 for 5-Fu resistance in colorectal cancer. Cell Biosci. 2017;7:17.

20. Yu B, Gu D, Zhang X, Li J, Liu B, Xie J. GLI1-mediated regulation of side population is responsible for drug resistance in gastric cancer. Oncotarget. 2017;8:27412-27.

21. Li C, Heidt DG, Dalerba P, Burant CF, Zhang L, Adsay V, et al. Identification of pancreatic cancer stem cells. Cancer Res. 2007;67:1030-7.

22. Stacy AE, Jansson PJ, Richardson DR. Molecular pharmacology of ABCG2 and its role in chemoresistance. Mol Pharmacol. 2013;84:655-69.

23. Peter ME. The flip side of FLIP. Biochem J. 2004;382:e1-3.

24. Frenzel A, Grespi F, Chmelewskij W, Villunger A. Bcl2 family proteins in carcinogenesis and the treatment of cancer. Apoptosis. 2009;14:584-96.

25. Weiswald LB, Bellet D, Dangles-Marie V. Spherical cancer models in tumor biology. Neoplasia. 2015;17:1-15.

26. Gu D, Liu H, Su GH, Zhang X, Chin-Sinex H, Hanenberg H, et al. Combining hedgehog signaling inhibition with focal irradiation on reduction of pancreatic cancer metastasis. Mol Cancer Ther. 2013;12:1038-48.

27. Kim EJ, Sahai V, Abel EV, Griffith KA, Greenson JK, Takebe N, et al. Pilot clinical trial of hedgehog pathway inhibitor GDC-0449 (vismodegib) in combination with gemcitabine in patients with metastatic pancreatic adenocarcinoma. Clin Cancer Res. 2014;20:5937-45.

28. Catenacci DV, Junttila MR, Karrison T, Bahary N, Horiba MN, Nattam SR, et al. Randomized phase Ib/II study of gemcitabine plus placebo or vismodegib, a Hedgehog pathway inhibitor, in patients with metastatic pancreatic cancer. J Clin Oncol. 2015;33:4284-92.

29. O’Neil BH, Scott AJ, Ma WW, Cohen SJ, Leichman L, Aisner DL, et al. A phase II/III randomized study to compare the efficacy and safety of rigosertib plus gemcitabine versus gemcitabine alone in patients with previously untreated metastatic pancreatic cancer. Ann Oncol. 2015;26:2505.

30. Chen W, Zhang X, Chu C, Cheung WL, Ng L, Lam S, et al. Identification of CD44 + cancer stem cells in human gastric cancer. Hepato-Gastroenterol. 2013;60:949-54.

31. Chen T, Yang K, Yu J, Meng W, Yuan D, Bi F, et al. Identification and expansion of cancer stem cells in tumor tissues and peripheral blood derived from gastric adenocarcinoma patients. Cell Res. 2012;22:248-58.

32. Fukamachi H, Shimada S, Ito K, Ito Y, Yuasa Y. CD133 is a marker of gland-forming cells in gastric tumors and Sox17 is involved in its regulation. Cancer Sci. 2011;102:1313-21.

33. Ishimoto T, Nagano O, Yae T, Tamada M, Motohara T, Oshima $\mathrm{H}$, et al. CD44 variant regulates redox status in cancer cells by stabilizing the $\mathrm{xCT}$ subunit of system $\mathrm{xc}(-)$ and thereby promotes tumor growth. Cancer Cell. 2011;19:387-400.

34. Wang T, Ong CW, Shi J, Srivastava S, Yan B, Cheng CL, et al. Sequential expression of putative stem cell markers in gastric carcinogenesis. Br J Cancer. 2011;105:658-65.

35. Jiang J, Zhang Y, Chuai S, Wang Z, Zheng D, Xu F, et al. Trastuzumab (herceptin) targets gastric cancer stem cells characterized by CD90 phenotype. Oncogene. 2012;31:671-82.

36. Rassouli FB, Matin MM, Saeinasab M. Cancer stem cells in human digestive tract malignancies. Tumour Biol. 2016;37:7-21.

37. Zhao D, Zou SW, Liu Y, Zhou X, Mo Y, Wang P, et al. Lysine-5 acetylation negatively regulates lactate dehydrogenase $\mathrm{A}$ and is decreased in pancreatic cancer. Cancer Cell. 2013;23:464-76.

38. Julian LM, McDonald AC, Stanford WL. Direct reprogramming with SOX factors: masters of cell fate. Curr Opin Genet Dev. 2017;46:24-36.
39. Goldman J, Eckhardt SG, Borad MJ, Curtis KK, Hidalgo M, Calvo E, et al. Phase I dose-escalation trial of the oral investigational Hedgehog signaling pathway inhibitor TAK-441 in patients with advanced solid tumors. Clinical cancer research: an official journal of the American Association for. Cancer Res. 2015;21:1002-9.

40. LoRusso PM, Rudin CM, Reddy JC, Tibes R, Weiss GJ, Borad MJ, et al. Phase I trial of hedgehog pathway inhibitor vismodegib (GDC-0449) in patients with refractory, locally advanced or metastatic solid tumors. Clin Cancer Res. 2011;17:2502-11.

41. Rahib L, Fleshman JM, Matrisian LM, Berlin JD. Evaluation of pancreatic cancer clinical trials and benchmarks for clinically meaningful future trials: a systematic review. JAMA Oncol. 2016;2:1209-16.

42. Lauth M, Bergstrom A, Shimokawa T, Toftgard R. Inhibition of GLI-mediated transcription and tumor cell growth by smallmolecule antagonists. Proc Natl Acad Sci USA. 2007;104:845560.

43. Kim J, Aftab BT, Tang JY, Kim D, Lee AH, Rezaee M, et al. Itraconazole and arsenic trioxide inhibit Hedgehog pathway activation and tumor growth associated with acquired resistance to smoothened antagonists. Cancer Cell. 2013;23:23-34.

44. Boehme KA, Zaborski JJ, Riester R, Schweiss SK, Hopp U, Traub $\mathrm{F}$, et al. Targeting hedgehog signalling by arsenic trioxide reduces cell growth and induces apoptosis in rhabdomyosarcoma. Int $\mathbf{J}$ Oncol. 2016;48:801-12.

45. Yang D, Cao F, Ye X, Zhao H, Liu X, Li Y, et al. Arsenic trioxide inhibits the Hedgehog pathway which is aberrantly activated in acute promyelocytic leukemia. Acta Haematol. 2013;130:260-7.

46. Platzbecker U, Avvisati G, Cicconi L, Thiede C, Paoloni F, Vignetti M. et al. Improved Outcomes With Retinoic Acid and Arsenic Trioxide Compared With Retinoic Acid and Chemotherapy in Non-High-Risk Acute Promyelocytic Leukemia: Final Results of the Randomized Italian-German APL0406 Trial. J Clin Oncol. 2017;35:605-612.

47. Jeon HM, Sohn YW, Oh SY, Kim SH, Beck S, Kim S, et al. ID4 imparts chemoresistance and cancer stemness to glioma cells by derepressing miR-9*-mediated suppression of SOX 2 . Cancer Res. 2011;71:3410-21.

48. Piva M, Domenici G, Iriondo O, Rabano $M$, Simoes BM, Comaills V, et al. Sox 2 promotes tamoxifen resistance in breast cancer cells. EMBO Mol Med. 2014;6:66-79.

49. Mu P, Zhang Z, Benelli M, Karthaus WR, Hoover E, Chen CC, et al. SOX2 promotes lineage plasticity and antiandrogen resistance in TP53- and RB1-deficient prostate cancer. Science. 2017;355:84-8.

50. Yang L, Xie G, Fan Q, Xie J. Activation of the hedgehogsignaling pathway in human cancer and the clinical implications. Oncogene. 2010;29:469-81.

51. Justilien V, Fields AP. Molecular pathways: novel approaches for improved therapeutic targeting of Hedgehog signaling in cancer stem cells. Clin Cancer Res. 2015;21:505-13.

52. Lauressergues E, Heusler P, Lestienne F, Troulier D, RaulyLestienne I, Tourette A, et al. Pharmacological evaluation of a series of smoothened antagonists in signaling pathways and after topical application in a depilated mouse model. Pharmacol Res Perspect. 2016;4:e00214.

53. Cheung HO, Zhang X, Ribeiro A, Mo R, Makino S, Puviindran V, et al. The kinesin protein Kif7 is a critical regulator of Gli transcription factors in mammalian hedgehog signaling. Sci Signal. 2009;2:ra29.

54. Liu H, Gu D, Xie J. Clinical implications of hedgehog signaling pathway inhibitors. Chin J Cancer. 2011;30:13-26.

55. Huang S, He J, Zhang X, Bian Y, Yang L, Xie G, et al. Activation of the hedgehog pathway in human hepatocellular carcinomas. Carcinogenesis. 2006;27:1334-40. 
56. Ma X, Sheng T, Zhang Y, Zhang X, He J, Huang S, et al. Hedgehog signaling is activated in subsets of esophageal cancers. Int J Cancer. 2006;118:139-48.

57. Fan Q, Gu D, Liu H, Yang L, Zhang X, Yoder MC, et al. Defective TGF-beta signaling in bone marrow-derived cells prevents hedgehog-induced skin tumors. Cancer Res. 2014;74:471-83.

58. He J, Sheng T, Stelter AA, Li C, Zhang X, Sinha M, et al. Suppressing Wnt signaling by the hedgehog pathway through sFRP-1. J Biol Chem. 2006;281:35598-602.
59. Bruns CJ, Harbison MT, Kuniyasu H, Eue I, Fidler IJ. In vivo selection and characterization of metastatic variants from human pancreatic adenocarcinoma by using orthotopic implantation in nude mice. Neoplasia. 1999;1:50-62.

60. Athar M, Li C, Tang X, Chi S, Zhang X, Kim AL, et al. Inhibition of smoothened signaling prevents ultraviolet B-induced basal cell carcinomas through regulation of Fas expression and apoptosis. Cancer Res. 2004;64:7545-52. 